\title{
A Amazônia Caribenha
}

\author{
The Caribbean Amazon
}

ARGEMIRO PROCÓPIO*

Rev. Bras. Polít. Int. 50 (2): 97-117 [2007]

\section{Introdução}

A Guiana, a Guiana Francesa, o Suriname e a Venezuela constituem importantíssimo conjunto de etnias, culturas, religióes e de visões de mundo no universo caribenho para onde os latinos americanos tardiamente estenderam as suas mãos.

Amazônicos mais por suas florestas do que pelo seu conjunto hídrico ou por suas políticas de integração, esses países, juntamente com o Brasil, relutam ainda em construir uma identidade sociocultural e econômica amazônico-caribenha entre si mesmos.

Se a Guiana Francesa fosse parte da Organização do Tratado de Cooperação Amazônica - OTCA, esses cinco constituiriam mais da metade dos membros da organização. Ligados pelos seus indígenas, pelos seus lavrados, por suas matas e por sua geografia física, nesses incógnitos espaços lindeiros, desenha-se uma geopolítica cultural merecedora de atenções e estudos nas relações internacionais pouco familiarizadas com as nações da Amazônia Setentrional.

A busca por identidades no universo da migração regional, da economia paralela dos garimpos, das drogas e dos madeireiros e o respeito às diferenças nessa Amazônia caribenha andam por conta própria. No triângulo Guiana-BrasilSuriname, o Estado ainda se mostra como um eterno ausente.

\section{Sociedade em espaços fronteiriços}

Crescendo a taxas médias de $5 \%$ nos últimos três anos, após substituir o guilder pelo dólar surinamense, com uma política externa ${ }^{1}$ de mãos dadas com a política econômica, Paramaribo abre-se em todas as direções possíveis e procura apoio tanto dos estadunidenses quanto dos bolivarianistas venezuelanos.

\footnotetext{
* Professor titular de Relações Internacionais da Universidade de Brasília - UnB e bolsista de produtividade em pesquisa do Conselho Nacional de Desenvolvimento Científico e Tecnológico - CNPq (procopio@unb.br).

1 EGGER, Jerome. Suriname por seus autores. Diplomacia, Estratégia, Política, no 5, janeiro-março de 2007, p. $128-143$.
} 
O aumento da capacidade de produção da alumina deve-se a empresas como a Suralco e a Billiton. A expansão dos investimentos na extração do ouro capitaneiase pela canadense Cambior. As pesquisas por petróleo são feitas pela espanhola Repsol, pela dinamarquesa Maersk ou pela Ocidental Petroleum Corporation dos EUA. Raramente essas atividades acompanham-se de cuidados ambientais compatíveis com a preocupação externada por governos dessas multinacionais nos fóruns internacionais onde se discutem os problemas ambientais amazônicos.

Explorando o quanto pode a vocação mineral local, os políticos surinamenses tais quais os brasileiros esquecem que minerais soltam uma única florada. As alternativas encontradas, como, por exemplo, plantação de novos canaviais, exportação de bananas, criação de camarões, mesmo sinalizando possibilidades de diversificação da pauta de exportação e mais emprego, sentem falta do apoio político da elite local, quase todo ele direcionado aos oligopólios da mineração e à economia clandestina.

O cidadão surinamense guarda, troca como quer o dólar surinamense e aplica como pode em qualquer instituição bancária. Essa liberação geral amarrase ao capital que a mineração e o contrabando de produtos chineses depositam em poucas mãos. Aí se inclui o ouro encontrado por milhares de depauperados garimpeiros do Brasil.

A República Popular da China ao investir em mineração o faz discretamente associada a grupos de diferentes nacionalidades. Ela e a Índia exibem presenças competentes em espaços outrora monopolizados por europeus e estadunidenses. A presença indiana, seja na Guiana, seja no Suriname, concorre no comércio local com a chinesa. Contudo, é imbatível a esperteza indiana no contrabando do ouro, inclusive daquele extraído ilegalmente do Brasil e espalhado pelo mundo através das janelas da contravenção amazônica.

Há poucos anos, a empresa China Zhong Heng Tai Investment, com tecnologia parecidíssima à da Embrapa na seleção de sementes, espaçamento, adubação e tratamento das mudas, estabeleceu com Paramaribo uma senhora parceria em plantações de palmeira de dendê. Orçada em 116 milhões, essa espetacular cultura emprega mais de mil técnicos chineses. Vista como uma iniciativa bioenergética, ela certamente aumentará a receita cambial do Suriname.

Apesar da excelente tradição da Embrapa, nesse setor, nota-se a ausência brasileira. Mesmo com todas as facilidades oferecidas pela vizinhança, faltam políticas para articulação setorial e regional da produção. Por inexistir investimento interno em agregação de conhecimentos e inovação, castra-se a cooperação técnica que demanda ciência e tecnologia.

A ilegalidade presente na movimentada rota de contrabando de drogas sintéticas, de madeira nobre, de diamantes, de pedras preciosas e de ouro, de produtos químicos controlados e de eletrônicos não precisa se dar ao trabalho de usar máscara no Suriname, país até hoje marcado pelas conseqüências do "golpe dos sargentos" em 1980. 
Há anos a contravenção no Suriname cresce como espinhoso problema para a segurança regional. As preocupações pela contenção do terrorismo internacional e pelo islamismo professado por quase metade da população na Guiana e no Suriname destacam esses caribenhos-amazônicos e a católica Venezuela nas agendas dos serviços de inteligência estadunidenses e da União Européia.

Igualmente as interferências externas impedem o fim do litígio entre Venezuela-Guiana e entre Suriname-Guiana por regiōes petrolíferas. Esse fato põe o estado brasileiro de Roraima numa explosiva situação geopolítica, bem ao lado de um tiroteio que tem de tudo para ferir esse estado setentrional com balas perdidas da política internacional.

\section{O silêncio que compromete}

O insuficiente diálogo sobre a cooperação, os problemas mal resolvidos na Comunidade Andina de $\mathrm{Nações}^{2}$ e a falta de iniciativas emudecem o multilateralismo na Hiléia desorientado na crise sistêmica. Tal crise questiona a legitimidade das democracias amazônicas, não pelo que prometem, mas pelo seu silêncio que compromete. As disputas entre Suriname e Guiana precisam de resolução por via pacífica. A favor da paz, o Brasil poderia desempenhar papel protagonista nessa intermediação.

Os focos de violência em espaços sociais aquém e além-fronteiras dos seis vizinhos amazônicos do Brasil avolumaram-se com a economia das drogas e com o agronegócio. Ampliou-se a procura por produtos químicos controlados, ampliou-se a procura pelos agrocombustíveis numa Amazônia sem vocação para substituir seus cerrados e suas florestas por canaviais.

Com a cooperação dos financiadores internacionais, o Suriname e o Brasil nos anos 1980 montaram infra-estrutura energética para a produção do alumínio. Duas décadas depois arcam com o pesado ônus da poluição ambiental. Pior, usam da eletricidade sem cuidados especiais com a água, esse recurso precioso, finito e agora abusadamente utilizado na produção do etanol.

Com os cursos de rios represados e interrompidos por barragens, a vida aquática sofre o prejuízo ambiental desse processo. Mesmo que a hidroeletricidade seja limpa e relativamente renovável, seu uso nas usinas sucroalcooleiras e nas atividades de mineração é, em geral, oneroso para a natureza. Esse fato, associado às queimadas das florestas e dos cerrados, realça a sustentabilidade do subdesenvolvimento brasileiro responsável por colocar esse país pobre e sujo na companhia de seis imundos ricos, considerados os maiores poluidores da terra.

Paradoxo dos paradoxos, a produção de energia limpa e renovável que se diz ser o etanol exaure a terra, gasta adubos, preteja o ar em sua colheita e consome

2 A propósito, ESTERMANN, Josef. Andine Philosophie. Eine interkulturelle Studie zur autochtonen andinen Weisheit. Frankfurt/M, 1999. 
absurda quantidade de água. Tal fato, direta ou indiretamente, transforma o exportador de grãos e de etanol igualmente em exportador de água.

O Suriname tem população que nem sequer alcança meio milhão de pessoas e seus políticos pensam também em ganhar fácil com a cana. Desigualmente repartida em área de 163.265 quilômetros quadrados, apenas a capital Paramaribo concentra cerca de 120 mil habitantes. A sociedade surinamense, de baixa imunidade ao crime organizado, assemelha-se com a família amazônica por suas florestas e pela gênese de suas debilidades estruturais ${ }^{3}$.

\section{O Suriname nas origens do Projeto Calha Norte}

O holandês, língua oficial, fala-se cada vez menos. O taki-taki, herança crioula, moda entre jovens, de certa forma transformou-se na língua franca do país. Independente desde 1975, essa sociedade serviu de palco entre 1980 e 1990 para golpes militares. Cinco anos depois do rompimento de seus laços coloniais com os Países Baixos, militares depuseram o governo civil, proclamando a República Socialista do Suriname.

Esse desafiador acontecimento - o socialismo de inspiração cubana dentro da comunidade amazônica - alarmou os EUA e, por extensão, o Centro de Informaçōes do Exterior. O Ciex do Ministério das Relações Exteriores é a caixa preta da ditadura até hoje escondida para não comprometer nomes de diplomatas vivos compromissados com a tortura e com a perseguição a exilados no exterior.

Motivados politicamente, cruzavam-se pelo Centro de Estudos Brasileiros ligado à Embaixada em Paramaribo membros do estamento militar, policial e dos serviços secretos surinamenses. Local impregnado de anticomunismo, repassava conceitos desatualizados da segurança e da defesa. Afinado com a Casa do Rio Branco, à época embebedada no fanatismo anti-subversivo, este "centro de estudos", bem afinado com o Ciex, repassava doutrinas e práticas elaboradas pelos serviços de informação estadunidenses.

A luta contra o socialismo por anos transformou-se no carro-chefe da cooperação diplomática entre Brasília e Paramaribo. Surgiu em tal contexto uma entre as tantas preocupações com a defesa do espaço amazônico logo incorporada ao Projeto Calha Norte, posto em marcha a partir de 1986. Antes, esforços das diplomacias declaradamente anticomunistas dos governos militares em boa parte dos países amazônicos convergiram para assinar em julho de 1978 o TCA, nascido com a inconfundível cor dos olhos do pragmatismo responsável da política externa brasileira ${ }^{4}$.

3 Ver LIER, R. A. J. Van. Sociedade de fronteira: uma análise social e histórica do Suriname. Fundação Alexandre de Gusmão. Brasília, 2005.

4 Ver PROCÓPIO, Argemiro. "Tratado de Cooperação Amazônica e suas implicações ecológicas. In: Ibero-Amerikanisches Archiv, Berlim, 1991. 
Num colossal erro de análise política, a diplomacia em Brasília julgava chegar do Leste Europeu, via Cuba, nas brechas da instabilidade amazônica, da surinamense, por exemplo, duros perigos. Em maior ou menor medida, tais perigos afetariam os projetos de vivificação das fronteiras e de construção de grandes estradas, ponta de lança do desmatamento em favor do agronegócio.

Equívoco insanável: as pressões partiam de sociedades hedonistas solidificadas em ferrenho consumismo na Europa Ocidental e nos Estados Unidos da América 5 . Precisamente aí se desfraldam bandeiras favoráveis a princípios como direito de intervenção, tutela internacional e soberania limitada ${ }^{6}$. Merece atenção a leitura dos conceitos de soberania territorial, segurança e defesa trabalhados por Rufin, Ruggie, Huntington e Badie 7 .

O despertar dos interesses por cuidados ambientais está acima do dito choque de civilizações ${ }^{8}$. Nascido de pressóes exógenas e raramente pelo respeito que a natureza e a vida merecem, o ambientalismo alienado responde pelos equívocos causados pela emergente ecocracia no aparelho burocrático do Estado, inclusive no surinamense.

O ambientalismo descompromissado com o social, ora por ameaças, ora por mimos embrulhados por ONGs dos países centrais, influenciou durante anos a formulação de políticas públicas de poucos resultados. A opacidade e visão alienada sobre a problemática ambiental hoje abrem as portas amazônicas para o renovado ciclo da cana-de-açúcar de alma colonial claramente presente na memória histórica do Suriname.

Equivocada, a aposta que o fim do comunismo antecedido pela queda do muro de Berlim traria paz legou à sociedade imensas dúvidas. Através da entrada surinamense, a subversão da corrupção soube aproveitar-se dos conflitos étnicos? Englobou espaços, principalmente os remexidos pelo narcotráfico. Afora isso, existe o fluxo quase contínuo de brasileiros deserdados da sorte - os bandeirantes do século XXI - ilegalmente empregados em garimpos dentro dos territórios da Guiana, Suriname, Venezuela e da Guiana Francesa.

Antigos colonizadores, os holandeses no Suriname ensinaram a língua. Exploraram contingentes de migrantes indianos e javaneses como substitutos da mão-de-obra escrava nas plantações de cana-de-açúcar e de arroz. Os filhos da África empobreceram e os da Ásia se enriqueceram. Atualmente o hinduísmo congrega cerca de um quarto do total da população, tornando-se a religião com o maior número de adeptos no Suriname e na Guiana.

5 Ver RUFIN, J.C. L'Empire et les nouveaux barbares. Paris: Lattès, 1991.

6 Ver RUGGIE, J. "Territoriality and Beyond: Problematizing in International Relations". International Organization, n. ${ }^{47}$, 1993, pp. 139-74.

7 Ver BADIE, Bertrand. O fim dos territórios. Lisboa: Instituto Piaget, 1995.

8 Ver HUNTINGTON, Samuel. O choque nas civilizaçôes. Rio de Janeiro: Objetiva, 1997.

9 Ver DEW, Edward. The Difficult Flowering of Suriname. Ethnicity and Politics in a Plural Society. Haia, Países Baixos. Nijhoff, 1978. 


\section{O garimpeiro brasileiro no Suriname e na Guiana Francesa}

A crise do desemprego no Brasil, a violenta perseguição aos maltrapilhos garimpeiros em áreas indígenas e o irrisório preço oferecido aos produtos da floresta neste quarto de século perdido e ainda em curso transbordaram para o Suriname número expressivo de paupérrimos migrantes brasileiros.

Hoje representam um considerável contingente da população local. Deserdados da sorte, sujeitos a maus-tratos e ao descaso consular, nem o governo, nem ninguém se lembra deles em suas políticas públicas. Mesmo as estatísticas os ignoram para dizer que esse problema inexiste. Contabilizados por estimativas díspares, algumas rezam: os brasileiros correspondem a quinze por cento da população do Suriname. Outras reduzem esse percentual pela metade.

Vitimados pelo Cartel de Suri, parte dos imigrantes brasileiros são explorados por organizaçōes criminosas oriundas do Líbano, da Índia e da Nigéria. Esses trabalhadores, marginalizados pelos que arquitetam os direitos humanos para suas bem remuneradas carreiras, recebem tratamento de escravos nos garimpos da floresta. Jamais viram a Organização Internacional do Trabalho e instituição alguma mover uma palha por eles.

Entre Caiena e Paris inexiste controle de bagagem pelo simples fato de considerarem esta última possessão francesa em terras continentais como rota interna. Companhias aéreas e empresas de navegação transportam para a Europa pequenas quantidades de pedras preciosas de grande valor, ouro e drogas com inacreditável silêncio das autoridades francesas nessa Amazônia, ainda parte do seu espólio colonial.

A administração francesa tampouco livrou essa herança napoleônica da ação dos narcotraficantes, dos madeireiros, dos garimpeiros e de outros agentes da degradação ambiental. Isso ensina que os problemas amazônicos jamais se esgotarão com a transferência da soberania para as mãos dos países centrais. Efetivamente, os problemas ambientais na Guiana Francesa, parecidíssimos aos dos seus vizinhos subdesenvolvidos, agora e no futuro, mostrar-se-ão em todas as horas da noite e do dia. Demoverão o mais ferrenho partidário da internacionalização em suas tentativas de lutar pelo fim da soberania nacional nos outros países amazônicos.

Em Caiena, sente-se a subversão da economia paralela fomentando o processo de integração num espaço colonial inteiramente démodé. Graças a essa subversão, intensificaram o intercâmbio e o fluxo de pessoas. Cresceu o comércio e ampliou-se a presença de brasileiros. O número desses compatriotas envolvidos nas diferentes etapas da economia informal corresponde ao aumento da presença do crime organizado europeu na sociedade amazônica. Tida ainda como um pedaço do velho mundo nessa parte do globo de florestas vivas, nessa colônia são as redes do crime que a livra do seu ostracismo sociopolítico. 
A substantiva integração da economia informal por intermédio do banditismo ultrapassa, nos países da Hiléia, as promovidas por iniciativas diplomáticas. O crime organizado integra de fato e desmoraliza quaisquer esforços oficiais em prol da organicidade da integração legal. Seu pragmatismo inovador reflete a modernidade nas suas dimensões mais cruéis. Nele a Segurança Ambiental vale menos que o dinheiro. Paralelamente à complexa interdependência de éticas distintas, observam-se no submundo desta possessão colonial atividades nas quais a força e a corrupção decidem as opções.

Neste lugar onde cidadãos da vizinhança amazônica padecem duros constrangimentos, conseqüência de seu status, a Guiana Francesa simboliza a herança colonial da ambição do eurocentrismo na Amazônia Continental. O processo de descolonização varreu a África nos anos 1960, porém tolerou o enclave desse departamento francês ultramarino bem na testa amazônica. Dessa forma, a França na Amazônia peca por sua ambição. Nem mesmo os milhares de imigrantes ilegais convencem Paris mudar a política responsável por afastá-la do convívio com os oito demais países amazônicos.

\section{Colonialismo francês na Amazônia}

A cobiça de Paris por pedaços amazônicos notou-se no Amapá, onde franceses entraram e retiraram-se, após pressionados, em 1840. Os ingleses penetraram no rio Branco e a questão dos limites brasileiros nessa região resolveu-se em 1904. Pelo laudo da Coroa italiana, deixaram de ser reconhecidos como do Brasil 19.630 quilômetros quadrados de terras amazônicas. Ou seja, não é só na Bolívia, Equador, Polônia ou na Alemanha que os territórios mudam de dono. O brasileiro já sentiu na própria carne a dor da amputação de partes reclamadas como suas ${ }^{10}$.

Os desígnios coloniais nesta parte hidrograficamente separada da bacia amazônica aportam custos também no domínio dos significados. É mostra da dominação colonial com a qual os países amazônicos ainda convivem.

Sem intenção de criminalizar a diáspora, precisa lembrar-se de milhares de brasileiros abandonados da sorte, sem as vantagens da cidadania em seu país natal, espalham-se pela Guiana Francesa. Sem estatísticas confiáveis para dizer se são vinte ou trinta mil, o certo é, destacada parte deles lá procura ouro e diamantes para máfias européias com negócios em Amsterdā, Antuérpia, Palermo e Marselha.

Vínculos históricos do Brasil com essa colônia remontam ainda às guerras napoleônicas. De fato, a Coroa lusitana, tradicional aliada dos ingleses, deixou lá sua resposta à invasão de Portugal. Marcou nesse ato, espécie de compensação pela fuga da família real de Lisboa para o Rio de Janeiro. Lavando a honra, a opção da casa dos Bragança recaiu na invasão desse espaço facilmente incorporado como

10 FERREIRA REIS, Arthur César. A Amazônia e a cobiça internacional. $2^{\mathrm{a}}$ ed. Rio de Janeiro: Edinova, 1965, pp. 118-119. 
propriedade do Reino Unido do Brasil, Portugal e Algarve. Parte do território brasileiro até 1817, pelo tratado de Viena, foi entregue à França.

Expressivo segmento da população da Guiana Francesa guarda raízes no estrangeiro. $\mathrm{O}$ êxodo da população na faixa etária ativa busca na metrópole oportunidades de emprego mais compensadores que na colônia. As portas da União Européia abrem-se para esses filhos amazônicos ocuparem funções recusadas pelos prósperos europeus.

Tal fato traz complicadores. Deixa Paris quase sem opção para o preenchimento dos postos pouco cobiçados na terra onde no passado, na ilha do Diabo, funcionou presídio de triste memória. Tem como alternativa ou tolerar os brasileiros católicos - hoje culturalmente mais distantes da França e ainda assim, mais dia, menos dia, acabam falando o francês - ou acolher os asiáticos hindus com bom inglês na ponta da língua. Atualmente, estes últimos constituem a maioria étnica das outras duas, antigamente chamadas de Guiana Inglesa e Holandesa.

$\mathrm{Na}$ virada do século XX para o XXI, muitos nordestinos e paraenses mudaram-se para a Guiana Francesa, a ponto de a festividade de expressão em Caiena ser o carnaval e, recentemente, o Círio de Nazaré. Isto sem esquecer da lusofonia lá indisfarçavelmente presente.

A teimosia de manter herança colonial na Amazônia, há décadas em desuso nas relações internacionais, leva Paris à sucessão de enganos. Por exemplo, a política indigenista implementada por este importantíssimo sócio da União Européia, ao ser vista pelos resultados, substantivamente pouco difere dos demais países do maciço da Guiana. Estão todas impregnadas de forte carga de contradiçôes, seja em nome da modernidade ou seja em nome dos euros distribuídos pelo Estado francês aos seus indígenas nessa possessão colonial.

$\mathrm{Na}$ Guiana Francesa, há indígenas recebendo mensalmente a chamada renda mínima, versão milionária do Programa Bolsa Família brasileiro. Morrem vítimas da cachaça e de outros vícios presenteados pela civilização do branco tal como aqui. Triste referência em termos de equívocos contra o indígena e contra as florestas tropicais, apesar de avançadas leis, estatutos e reservas, o Brasil tem pouco para ensinar à França e vice-versa.

A ilusória felicidade do bom selvagem amansado pelo dinheiro leva o 'sindicalismo indígena' a pender para o lado que satisfaz o seu paladar ou onde se vendem drogas e bebidas alcoólicas a melhor preço. $\mathrm{O}$ custo de vida nesse pedaço de mundo é seguramente o maior na Amazônia Continental.

\section{La Gabrielle no final do iluminismo}

Considerando-se o critério ultramarino da possessão colonial, a França divide com o Brasil sua maior fronteira. Mesmo assim, a carne bovina nacional quando vendida legalmente em Caiena chega através do portal do atlântico norte percorrendo o trajeto Belém, Marselha e, por fim, Caiena! Daí seu exagerado 
preço, responsável pela preferência à carne bovina e bufalina brasileiras, baratas, de excelente sabor, qualidade e fartas no mercado negro.

O conhecido protecionismo agrícola francês, camuflado por barreiras fitossanitárias, propositadamente dificulta a aproximação pelo comércio da sociedade guianense com todos os países amazônicos. O controle fitossanitário em sociedades cujos povos bebem água dos mesmos rios, sentem as mesmas chuvas, consomem frutas e produtos agrícolas de um único universo pedológico equivale a tiro saído pela culatra por duas razões.

A primeira ao onerar o contribuinte francês na manutenção de estrutura colonial ultrapassada. A segunda por causa da integração paralela nos espaços sociais aquém e além dos marcos divisórios move-se independentemente dos caprichos de Paris. Compra-se e vende-se no mercado paralelo sem a mínima preocupação com o humor da metrópole.

Nessa parte do mundo, a França enfrenta problemas de segurança e vigilância, como qualquer outro país subdesenvolvido. Isso custa caro aos seus contribuintes. Para tornar mais rentável esse espólio colonial, projetos de plantações de cana-deaçúcar para o etanol estão em marcha. Nessa hora, silenciam-se as preocupações do governo francês pela devastação florestal.

O jardim botânico La Gabrielle maravilhou Dom João VI que trouxe de lá espécies nobres. Daquela horta do iluminismo francês à atual plataforma de lançamento de foguetes do Centro Espacial em Kouru, o tempo nunca apagou da memória o desrespeito pelos Direitos Humanos nos presídios nesse pedaço amazônico à espera de algum dia tornar-se Estado.

A coroa portuguesa tinha intenções de plantar no Brasil, para depois vender na Europa, espécies exóticas de alto valor. Daí a admiração por La Gabrielle, fonte de inspiração para os projetos de um horto florestal no Rio de Janeiro, no Pará e outro no Maranhão. Mangueiras (Mangifera indica), gengibre (Zingiber officinale), anil (Indigofera tinctoria), bogari (Jasminum Sambac), jaca (Antocarpus integrifolia), canela de casca fina (Cinnamomum zeylanicum), cravo das Molucas ou das Ilhas das Especiarias (Syzygium aromaticum), pimenta africana (Piper nigrum), nós moscada (Myristica aromatica Lam), isso e mais, o iluminismo tardio lusitano pretendia explorar. Um porém: a fase magna do comércio das especiarias de alto preço havia passado há décadas ${ }^{11}$.

O péssimo tratamento ao estrangeiro lá revive a desolada imagem transmitida de suas colônias penitenciárias com trabalhos forçados para deportados. Resumindo, a Ilha do Diabo, hoje um centro turístico, guarda duras recordaçóes de passado singularizado no presente: atualmente, a segregação e a má acolhida aos brasileiros vizinhos parecem rotina do tratamento dispensado aos que da periferia migram para a União Européia.

11 Ver TORRES, Milton. O Maranhão e o Piaui no espaço colonial: a memória de Joaquim José Sabino de Rezende Faria e Silva. São Luís, Instituto Geia, 2006, p. 185. 


\section{A valsa ideológica da Guiana}

A República Cooperativa da Guiana logo no apagar do seu passado colonial com Londres, em 1966, aproximou-se da União Soviética. Com o esfacelamento dessa última até hoje, ela deixa-se mimar pela República Popular da China. A presença de Pequim em Georgetown intriga tanto as antigas potências coloniais quanto os EUA.

Sede do Caricom, ainda assim a Guiana é esquecida pelo Brasil. Diplomatas brasileiros aceitam aquele posto geralmente em troca de melhor contagem de tempo, por rápida promoção e remoção garantida para servir no eixo Elizabeth Arden. Com raras exceções, quem procede usualmente assim com a Guiana, o mesmo comportamento adota em relação à quase totalidade da África, aos pobres da Ásia e aos demais assemelhados com o Brasil.

O conhecimento superficial das relações interétnicas, a tradição de ignorar que são de veludo as barreiras ou fronteiras dividindo as etnias amazônicas, a insistência em ignorar que os nativos das florestas e dos lavrados vêem na terra um bem cultural e jamais um bem de produção, tudo isso dificulta a presença de qualidade dos agentes do Estado na sociedade amazônica.

O poder da cultura na Guiana e no Suriname divide-se em mãos de descendentes de escravos negros, de muçulmanos convictos, de hindus e raramente nas dos indígenas ou dos poucos descendentes de espanhóis que há séculos lá pisaram. Apesar de ser um instigante exercício para estudiosos da sociedade da Amazônia Setentrional, essa matéria da sociologia comparada sobre essas sociedades permanece ainda como um projeto a ser iniciado.

Dados obtidos em março de 2007 davam conta de que cerca de 10\% dos presidiários em Boa Vista tinham a nacionalidade guianense. Abuso de drogas, roubo de veículos e outros delitos típicos dos peixes pequenos respondiam pela maioria das condenaçôes.

Do total de 850 mil almas guianenses, 12 mil delas, com registro duplo, vivem em Roraima, estado com cerca de 325 mil habitantes, dos quais 250 mil concentram-se em Boa Vista. Simpatizantes radicais do pragmatismo circunstancial, assumem a nacionalidade brasileira ou guianense segundo suas necessidades.

Mais numerosos que os guianenses em Boa Vista - ainda que contagens ocasionais digam o contrário - os brasileiros na Guiana garimpam o ouro, diamantes e serram árvores. Como mulas, transportam drogas e produtos químicos controlados em espaços sociais transfronteiriços. A maré de ilícitos das máfias madeireiras nesta parte setentrional blinda toda uma macroestrutura a facilitar o contrabando de produtos de alto valor. Corrompe e impede investigaçóes levando ao senhorio dessa bem organizada rede de contravenção.

No território guianense, quase quarenta vezes menor que o brasileiro, os mais destacados centros urbanos localizam-se no litoral. Georgetown, Linden e New Amsterdam estão de costas para essa terra, assim como o Brasil dá a sua para 
eles. Isso apesar da fortíssima identidade comum legada pela progênie africana a ambas as partes.

Sua população nem três vezes maior que a de Roraima e os 1.472 quilômetros de fronteira sinalizam existir entre Guiana e Brasil uma identidade caribenha reveladora de 'amazoneidades' próprias a ambos. Ainda assim, da única ponte a uni-los fisicamente, apesar de várias vezes paga, apenas suas colunas inacabadas avistavam-se sobre as águas do rio Tacutu.

Com ou sem ela, quinquilharias, computadores e até material cirúrgico contrabandeados do Império do Centro aí transitam. Por esse caminho antigamente entravam o arroz e o açúcar guianense. Esse último vendia-se a menos da metade do preço daquele transportado do longínquo Nordeste para Boa Vista.

A febre garimpeira assolou o Brasil nos anos 1980. Agora voltou e agride os países vizinhos. A experiência nacional com os garimpos de ouro e diamante desempenha papel protagonista, seja na descoberta de novos veios, seja em suas técnicas de exploração. No rio Cuyuni, afluente do Essequibo, dragas parecidas às que tanto poluíram o rio Madeira em passado recente lá provocam os mesmos problemas ambientais.

A população de Georgetown, capital abaixo do nível do mar, protege-se por velhos diques construídos pelos ingleses. Por causa da má construção e raramente restaurados, a capital sofreu há poucos anos terríveis inundações com perdas humanas. Pelo fato de ser Georgetown, e não New Orleans, o espaço dado pela mídia a essa tragédia jamais correspondeu à gravidade do fenômeno.

A velocidade das águas dos rios na desembocadura para o mar depende de correntezas que, por sua vez, dependem de canais naturais e da profundidade das águas. $\mathrm{O}$ assoreamento provocado por garimpos destruidores de barrancos na cata do ouro certamente apressa enchentes e catástrofes.

Pelo fato de expressivo número dos garimpeiros ser brasileiro, o crime de retirar ouro e diamante certamente custará demais ao Brasil. Isto, apesar da maior parte dessa riqueza cair nas mãos das forças policiais e dos políticos guianenses, para depois acabar nas mãos das máfias euro-asiáticas. No bolso do garimpeiro ripário, quer dizer, daquele que freqüenta os bancos de um rio, fica praticamente nada dessa riqueza.

\section{O esquecido país sede do Caricom}

Porta voz dos caribenhos no grupo do Rio, prometendo entrar nessa agremiação como membro pleno e não só como representante dos países do Caribe, a Guiana dá ao Brasil a mesma importância que a diplomacia do Rio Branco reserva para ela, ou seja, nenhuma. Ao contrário das representações diplomáticas brasileiras na Europa e nos Estados Unidos da América apinhadas de funcionários, Georgetown tem como embaixador um ministro de segunda classe e um diplomata para auxiliá-lo. 
Sede da Comunidade do Caribe, entre seus quinze membros, onze são anglófonos insulares, um francófono - o Haiti - e três continentais, Suriname, Belize e a própria Guiana. Também associada ao Aosis (Associação dos Pequenos Estados Insulares), esse vizinho demasiadamente vulnerável às mudanças climáticas particularmente sofre com o aquecimento global responsável pelo aumento do nível do mar. Ou seja, a paz com a vizinhança por parte do Brasil depende particularmente dos cuidados ambientais que o país deverá ter para consigo mesmo. O melhor cartão de visitas que o Brasil pode ter é o respeito para com seu próprio povo e o poder de vigiar e punir as elites que legislam em causa própria, outorgando a si e a sua prole salários entre os mais abusivos do mundo.

Surinamenses e guianenses, vizinhos ausentes na diplomacia, na academia, na mídia e ignorados pelos empresários, com a crise econômica brasileira através das portas da economia informal, estão bem mais presentes do que antes no cotidiano lindeiro.

A diáspora agora sentida pelo brasileiro dentro da própria casa atormenta intensivamente os guianenses há décadas. Acredita-se que outro tanto de população equivalente a de Georgetown viva no Reino Unido, nos Estados Unidos da América e no Canadá sem laços ou saudades da pátria mãe. Ao contrário do Brasil, Bolívia, Colômbia, Equador e Peru, cujos imigrantes remetem dinheiro para a família, diz-se que o guianense é relativamente avarento. Quando sai do país, volta jamais.

Triturada pela empresa de capital moscovita nominada Rusal, depois de seca, a bauxita de excelente qualidade segue em graneleiros para a Europa em quantidades muitíssimo superiores às declaradas. A Guiana, miniatura do Brasil, abriga poderosos e discretíssimos grupos chineses, sempre trabalhando em silêncio. A China passa assim a tomar espaços antes ocupados pelo Reino Unido ou pelos Estados Unidos da América.

A Guyana Sugar Coorporation passou de mãos canadenses para chinesas. Essas já transformaram projetos em realidade, tais como a instalação de usina de etanol e, bem próximo dali, de uma termoelétrica incrivelmente parecida em tecnologia com as usinas do lado de cá, alimentada com bagaço da cana. O que o Brasil intenciona fazer com o apoio de Washington, os guianenses já adiantaram trabalhando com Pequim, sempre presente na ajuda técnica.

As exportações de madeira contrabandeada e subfaturada paulatinamente empobrecem áreas florestais guianenses que, a continuar o ritmo da devastação em futuro próximo, unir-se-ão às áreas devastadas do lado brasileiro.

\section{A luta por territórios}

No pertinente à inconformidade da Venezuela com a decisão de um tribunal arbitral internacional montado em Paris, isso ocorreu porque acertos políticos entre a Rússia e a Inglaterra viciaram o tal laudo arbitral de 1899, que foi manipulado 
por um prussiano de origem russa. Desde então a reclamação venezuelana por terras na Guiana, como um vulcão, hora lança cinzas, hora se acalma.

Menos de década depois dos problemas com o laudo, em 1908 o General Juan Vicente Gomes tentou em vão alguma saída. Quarenta anos depois, finda a Segunda Guerra Mundial, o romancista e Presidente Rómulo Gallegos na Conferência dos Estados Americanos em Bogotá externou sua total inconformidade com o laudo arbitral.

O Presidente Perez Jimenez usou da Organização dos Estados Americanos e das Nações Unidas batendo sempre na tecla da desaprovação de tal laudo. Tal insistência incomodava cada vez menos os ingleses, cientes de que suas colônias, como no jogo de dominó, uma a uma iam proclamando suas independências. Após a deposição de Jimenez por golpe militar em 1958, a posição de flexibilidade dos ingleses mudou; talvez por causa de suas derrotas diplomáticas para com o Egito relacionadas ao Canal de Suez.

A aceitação de Londres das reivindicações de Caracas certamente repercutiria na quase dúzia de ilhas anglófonas no Caribe, fato suficiente para Londres endurecer até diante dos delicados recados emitidos por Washington a favor da Venezuela. Naquele tempo, ainda no nascedouro, a revolução cubana deixou os EUA em maus lençóis.

Washington exigia dos aliados ação para barrar a influência de Fidel Castro. Rómulo Betancourt se prestou a isso. Servindo aos interesses estadunidenses contra Havana, levantou a questão da disputa com Georgetown. Recebeu um explícito apoio de Washington. Pressionada, Londres finalmente concordou criar comissão de especialistas para rever os documentos e iniciar negociações ${ }^{12}$.

Efetivamente, em fevereiro de 1966, Caracas e Londres assinaram em Genebra memorando buscando mecanismos para resolver o problema territorial. Acontece que, semanas depois, no dia 25 de maio de 1966, a República Cooperativista da Guiana declarou sua independência. Os venezuelanos continuaram a ver navios, sem definição nenhuma para solução dessa gigantesca disputa por território, parte dele provavelmente abarrotada de petróleo.

Manifestando boa vontade para com as elites no poder da nova e vizinha república, a Venezuela numa amabilidade ímpar apressou-se em reconhecê-la propondo sua entrada na Organização das Nações Unidas.

A nova liderança em Georgetown apoiada por Cuba e URSS esnobou inflexibilidade. Concordaram sim em reunir comissão tratando do assunto, contudo espertamente nem sequer decidiram sobre a agenda. Em 1970, quem diria, venezuelanos apoiados pelos EUA e os guianenses orientados por Cuba, no Protocolo de Port of Spain - num adendo sobre o Acordo de Genebra firmado em 1966 entre a Venezuela e a Grã-Bretanha - congelaram a disputa por 12 anos.

12 Ver GARAVINI, di Turno A. Politica exterior de Guyana. Instituto de Altos Estudios de America Latina. Universidad Simon Bolivar. Caracas, 1988. 
Mal percebendo a astúcia da estratégia dos guianenses, soprada por Havana de empurrar com a barriga o máximo possível a disputa, Rafael Caldera buscou o caminho do diálogo. Tentou fortalecer laços bilaterais com a Guiana até então frouxos como os que mantinha com os brasileiros. Nesse espírito, Georgetown viu com alegria o Protocolo de Port of Spain ser ratificado pelo Congresso em Caracas.

A inversão das alianças, ou seja, o distanciamento de Caracas com Washington e posterior aproximação com Havana, assim como o esfriamento de Georgetown com Cuba e rápido aquecimento bilateral com os Estados Unidos da América, deixou tudo exatamente na mesma. Chávez certamente quer evitar equívocos de seus antecessores. Encarando com realismo responsável a diplomacia de Georgetown, longe de subestimar o poder étnico guianense com dúzia de votos no caribe anglófono, Chávez sabe ser suicídio político fazer da Guiana o que Saddam Hussein fez do Kuwait.

Carlos Andrés Perez, o primeiro presidente venezuelano a viajar à Guiana, apresentou-se com um cesto de propostas orgulhosamente desprezadas por Georgetown. Perez chegou a proclamar que abandonaria desideratos históricos, abriria mão do leste de Essequibo em troca de uma faixa ao longo da costa, no território setentrional acima do rio Cuyuni. Prometeu em troca construir uma hidrelétrica no alto Mazaruni, afluente do Essequibo. Nenhuma oferta foi aceita pela Guiana.

Sem perder a paciência com esse coelho da cartola do Tio Sam, Caracas agora acompanha com olhos de condor a programada diplomacia de Georgetown. $\mathrm{O}$ assunto atualmente permanece na pachorrenta mesa de acordos da ONU. Até os mediadores que aproximariam os dois países morreram pela idade. $\mathrm{O}$ último deles, um jurista de Barbados, faleceu no início de 2007.

\section{Disputas por fronteiras entre a Guiana e o Suriname}

Enquanto isso, espalhados nas escolas e nos ministérios, em todos os mapas venezuelanos, lê-se grande parte da Guiana anexada à Venezuela com a seguinte frase: Zona en reclamación. A maioria dos governos americanos no "esprit de corp" da latinidade concorda com as aspirações de Caracas.

Sabendo de antemão a posição histórica do Brasil diante das terras controladas pelo imperialismo inglês e dos problemas com a opinião pública interna por parte de qualquer país irmão que ousasse se manifestar contra essa postura, Chávez se opõe a eventual projeto do Brasil na Guiana. Antes de tudo, porque eles sinceramente inexistem. Os engavetados são de tão pequena envergadura que nem sequer atraem polêmicas. Por exemplo, melhorar estradas de terra, drenar, acascalhar, refazer pontes de madeira em petição de miséria, nada disso incomoda ninguém, nem mesmo as comunidades indígenas porventura ali existentes.

A Guiana anda prensada por dois vizinhos. O primeiro é a Venezuela, militarmente bem equipada, relativamente forte, com boa capacidade de 
mobilização. Culturalmente afastada dos guianenses de origem indiana e africana, a inexistência de política cultural de aproximação é o pecado mortal de Caracas. A arrogância histórica das tradicionais elites venezuelanas abriu espaço para a presença de Dionísio nos sonhos nacionalistas.

O segundo poder a pressionar Georgetown está concentrado em Paramaribo. O Suriname, por causa dos seus conflitos políticos e étnicos, anda tão aperreado quanto a Guiana, que sempre foi o seu retrato falado. Com esse último, disputamse terras nas cercanias do rio Corentyne e áreas próximas a Neiuw Nickerie. Existe igualmente litígio por áreas marítimas a serem julgadas em Washington pelo Tribunal Internacional do Direito do Mar. A marinha surinamense já expulsou canadenses trabalhando para o governo guianense nessas águas.

Para desnortear Georgetown, um apaixonado namoro de Caracas com Paramaribo anda em curso com farta venda de óleo cru a preços realmente convidativos e outros mimos da Petrocaribe. Sob esse aspecto, Caracas generosamente auxilia as nações caribenhas, velhas viúvas do bipolarismo mundial. Em troca, elas respaldam politicamente o bolivarianismo. Antígua e Barbuda, São Vicente, Granadinas e Dominica, comungando com o antineoliberalismo, aplaudem a marcha da expansão da Alternativa Bolivariana para as Américas em contexto de um ciúme cada vez menos velado por parte de Brasília.

Diante desses fantasmas externos a assombrar a Guiana, os dois partidos políticos no poder, engalfinhados em disputas étnicas, agora se entendem melhor. Em resumo, polícia e exército concentraram-se em mãos da progênie africana e o poder da economia e dos tribunais superiores em mãos indianas ${ }^{13}$. O PPP, Peoples Progress Party, fundado por Cheddi-Jagan, era de inspiração marxista. O PNC, People National Congress, de etnia africana, liderado por Lindon Forbes Burnhan, famoso por sobreviver cerca de duas décadas na presidência por meio de fraudes e corrupção, manteve-se no poder apoiado pelos EUA ${ }^{14}$. Desde então, o PPP, sustentado pelos indianos, controla o poder. Recrutaram afro-descendentes e os distribuíram em atrativos postos para aliviar tensões, preferencialmente os diplomáticos, repletos de mordomias e vazios de poder.

A falta de recursos humanos e o desconforto vernacular nos espaços sociais lindeiros do Brasil com a Guiana e o Suriname deixaram que paradoxos erguessem ali algo piorado da torre de Babel. Realmente, ao contrário do ensinamento bíblico, mesmo falando línguas distintas, lá crescem as estruturas do contrabando tribalizado. Para agravar a situação, notável número de jovens brasileiras entrega-se às redes de prostituição nesses países em busca do pão cotidiano. Quem tenta ganhar a vida em Georgetown, perde-a rapidamente contagiada pela Síndrome da Imunodeficiência Adquirida. Dentre as prostitutas, aquelas que regressam ao lar, vão para casa para morrer. Isso caso encontrem

13 Ver ROMERO, Rita Giacalone de (org.). Guyana hoy. Carácas. Corpoandes/Editorial, 1982.

14 Ver RIVIERE, Peter. O indivíduo e a sociedade na Guiana. São Paulo, Edusp, 1999. 
algum garimpeiro sortudo e de alma generosa disposto a pagar a passagem da volta sem volta.

Difícil e factível, esse acordo de boas intenções promoveu a valsa dos diamantes no mundo. Ninguém diz exatamente sua procedência propositalmente mascarada. Poucas centenas de quilômetros separam Georgetown da fazenda, ex-propriedade do Reverendo Din Jones, responsável pelo envenenamento de centenas de seus seguidores. Naquele lugar de triste memória, trabalham brasileiros na busca do ouro para empresários chineses e canadenses. Todavia, não é só do garimpo que vivem os miseráveis brasileiros lá esquecidos por Deus.

O despertar pela bioenergia lentamente acontece na Guiana e no Suriname, fato que talvez algum dia ressoe entre o pequeno e tímido empresariado roraimense e amazônico. Georgetown e Paramaribo sabem que da tradição açucareira para a do etanol o salto é deveras pequeno.

Somando os empregos indiretos e diretos oferecidos pela indústria açucareira, esse setor emprega quase um quinto da população guianense. Os dólares obtidos com a exportação açucareira, inclusive do seu genuíno açúcar demerara, chegaram nos últimos dois anos à casa dos US\$ 250 milhôes.

\section{A ausência brasileira}

O baixo custo da mão-de-obra, clima apropriado a culturas tropicais, luminosidade, água, abundância de terras férteis e de matérias primas e o fato de estar no hemisfério norte, relativamente perto dos grandes mercados consumidores, nada dessas vantagens comungadas por outros tantos países pobres ajuda a Guiana ou o Suriname. E, a bem da verdade, nenhum dos países amazônicos.

Produtos made in Brazil, há anos gradativamente substituídos nas gôndolas dos supermercados dentro do próprio Brasil por aqueles made in China, tampouco existem nas prateleiras do comércio vicinal nessa parte do Caribe. Para pensar que nem tudo está perdido, nas relações bilaterais Brasil-Guiana, o coco salva as aparências. Caminhões cheios deles destinados ao mercado consumidor brasileiro sempre atolam e caem nos buracos da única estrada a unir esses dois vizinhos. De terra, a BR-401, nas proximidades do rio Takutu, a espera há anos de uma ponte, é o retrato falado do descaso na integração regional.

O gigantesco delta do rio Essequibo raramente visitado por alguma embarcação de bandeira brasileira seria excelente canal para transportar a baixo custo mercadorias em variadas direçōes. Todavia, a falta de vontade política, que castra iniciativas, obriga os produtores a restringir o comércio amazônico nacional para dentro das fronteiras brasileiras.

Grande paradoxo da Guiana, fenômeno de difícil compreensão sociológica, diz respeito ao legado inglês presente em seu sistema educacional beirando níveis de excelência. Comparada aos demais países amazônicos, a educação guianense, por ser de especiosa qualidade, vitaminou a diáspora. Repetindo o escrito 
anteriormente, guianenses que saíram nos anos 1980 jamais voltaram. Nem sequer ajudam financeiramente os que ficam ${ }^{15}$.

Com aproximadamente $80 \%$ do território desabitado, a cada dia arquivase o projeto da Guiana transformar-se juntamente com o vizinho Suriname no sustentáculo agrícola das nações insulares do Caribe, vítimas em escala crescente do aquecimento global.

Caracterizadamente multirraciais e multirreligiosos, demora demais a hora para que os africanos, indianos, chineses, europeus, ameríndios e brasileiros melhor se entendam dentro das fronteiras guianenses e surinamenses. A visão inconsistente dos problemas internos das elites de olhos no enriquecimento fácil, ao invés de transformá-los em nações com prósperos e apropriados negócios, os levou à estagnação econômica quase tão longeva quanto a brasileira ${ }^{16}$.

O porto de águas profundas e a zona de exportação da ilha de Hogg na foz do rio Essequibo - ainda que dentre os melhores do subcontinente - perderam a importância estratégica como centro de transferência de carga para o Brasil, Suriname e Venezuela. Isso porque o Suriname e o Brasil transformaram-se em verdadeira porta de entrada do contrabando.

Visto que todos no subcontinente pretendem ao mesmo tempo transformarse em Meca da exportação, complicam-se regionalmente as disputas por parcerias estratégicas. No traiçoeiro contexto de interdependências assimétricas, os amazônicos se fazem mais telespectadores do que atores do processo da sua inserção nas relaçōes internacionais.

Até hoje sem resposta por parte do já mencionado Tribunal Internacional dos Direitos do Mar, o litígio marítimo entre o Suriname e a Guiana, seja seu resultado favorável ou desfavorável a Georgetown, descortina negativos cenários para a cooperação amazônica. A Guiana, ao defender seus interesses, insiste em entender tais terras como suas e jamais venezuelanas ou surinamenses.

Isolada pelos vizinhos a leste e oeste, tampouco o Brasil, no sul, brinda a Guiana com a atenção que a boa vizinhança exige. Pelo andar da carruagem do Itamaraty, falta demais para considerar a Guiana como excelente portal da Comunidade do Caribe (Caricom).

Do outro lado do mundo, surgiu mais ativa e competente a diplomacia de Pequim, há anos ocupando o vácuo da burocracia do saber das elites brasileiras. Prestando assistência técnica de qualidade, daquela que os especialistas põem mãos à obra deixando de dedicar-se apenas a relatórios, os chineses conseguem resultados nem sequer sonhados pela Agência Brasileira de Cooperação do Ministério das Relações Exteriores, pródiga em telegramas e em relatórios e em falta de ação.

15 Ver RIVIÈRE, Peter. O indivíduo e a sociedade na Guiana. São Paulo. Edusp, 1999.

16 Ver ROMERO, Rita Giacalone de. Estudio historico de la Guyana Britanica del descubrimiento e la formacion del movimento independentista. Mérida, Venezuela. Librería Universitaria Fundacipol, 1982. 
No modismo da bioenergia, cada um planta o que quer, quando, onde e como quer. A cooperação multilateral com regras mínimas para monitorar essa ou aquela prioridade entre os oito amazônicos praticamente inexiste. Nessas horas, sente-se muitíssima falta de uma Organização do Tratado de Cooperação Amazônica atuante e dinâmica. Resumindo, na periferia a memória é curta.

Olvidam-se rapidamente desastres econômicos de superprodução oriundos de monoculturas para a exportação. $\mathrm{O}$ café mais o açúcar pariram catástrofes e arruinaram produtores repetidas vezes. Ainda assim os países produtores esqueceram a lição. Governo algum da Amazônia luta por produção integrada e por política de exportação que deixe de lucrar com as desgraças do outro.

\section{Pequim e Washington na Amazônia Caribenha}

Além dos graves problemas de demarcação de fronteiras, a ex-colônia inglesa, a Guiana, tem porque se preocupar por ser o país amazônico com a mais alta incidência de portadores de Síndrome da Imunodeficiência Adquirida (Sida/ Aids). Os EUA, em seus programas de cooperação, colocam esse país, juntamente com o Haiti, nas prioridades da Usaid.

Mesmo com a alta qualidade técnica dessa Agência, que costuma funcionar no mesmo espaço físico das embaixadas dos EUA, ela perde em dinamismo para a representação diplomática da China em Georgetown.

Na política, toda caridade tem seu valor de troca. O governo norte-americano guarda segredo sobre a quantas anda o polêmico projeto de uma base espacial que tanto irritou Caracas. Tal iniciativa havia sido originalmente programada para ser construída no Essequibo pela Beal Aerospace Technologies, que cessou seus negócios em outubro de 2000.

A entrada dos chineses na Amazônia através do corredor setentrional formado pela Guiana e pelo Suriname revela o interesse da República Popular da China pelas reservas de petróleo, gás, biodiversidade, madeira e pela abertura de caminhos para desova de seus produtos no Caribe e no extremo norte da América do Sul. A escassez na China de matérias-primas dita o rumo da sagaz presença do dragão na Amazônia.

Pela estrada da ilegalidade, igualmente conhecida pela fama do trânsito dos produtos chineses inundando o Brasil setentrional, a BR-401, Boa Vista-Bonfim, conecta o contrabando rodoviário ao fluvial. Isso se vê em águas guianenses, no rio Maú Miang, por exemplo. Pela República da Guiana transitam produtos chineses e recentemente até indianos, como jóias e tecidos destinados ao consumidor desinteressado em saber se o que compra é contrabandeado ou não, se desemprega ou não.

Fronteiras com vigilância de baixa qualidade e a notável corrupção interna a receber de braços abertos as ofertas do crime tribalizado fazem o Brasil parecer terra de ninguém. 
Nota-se que Washington incrementa sua parceria com Georgetown contrapondo-se com auxílio humanitário e econômico àquela que Chavéz oferece a alguns outros amazônicos. Tendo no bolso um pacote de ajuda à educação, merenda escolar e moradia bem menos generoso que os US $\$ 16$ bilhões investidos em projetos sociais garantidos pela política bolivarianista de cooperação na vizinhança, Washington tardiamente amplia suas prioridades para uma maior presença na sociedade amazônica.

Principalmente por causa das disputas territoriais com a Venezuela, sobra troca de informaçōes entre os serviços especializados das Forças Armadas e dos serviços de inteligência da Guiana com os EUA. Quanto aos demais amazônicos, eles calam-se diante desse conflito.

Inexistindo um projeto integrado de defesa, a Guiana depende da cooperação bilateral com os EUA. A falta de vontade política de Georgetown na aproximação com os latino-amazônicos e vice-versa traduz recíproca ignorância. Vem daí a dificuldade da reversão do quadro de apatia pela integração amazônica. Arranjos bilaterais aplicados a fenômenos multilaterais prejudicam tentativas de reforço à segurança de feição transnacional entre Brasil, Bolívia, Colômbia, Equador, Guiana, Peru, Suriname e Venezuela.

Esquecidas das lições da história, as delongas diplomáticas dependentes das fragilidades internas postergam o fortalecimento da segurança coletiva. Deixam até mesmo atividades agropecuárias ao alcance de sabotagens e do bioterrorismo. A prevenção para conter futuras pragas nos canaviais com chances de estender às outras lavouras é uma necessidade.

Falta, outrossim, descobrir as causas dos surtos da febre aftosa que em passado recente atingiram rebanhos comprovadamente vacinados. Diante do leque das debilidades da defesa na Amazônia - também da defesa fitossanitária - os perigos nem sempre se percebem a tempo, notadamente os existentes na Guiana e no Suriname.

Prevenção pede integração com minimização das divergências e maximização das convergências. Envolve proposições conjuntas e desprendimento em prol do trabalho cooperativo circundado por variáveis particularmente dinâmicas.

Segurança, monitoramento de fronteiras e defesa merecem pauta na agenda diplomática dos oito. O déficit de informaçôes sobre a Guiana e demais países amazônicos entre si mesmos permanecerá insolúvel se persistir a crença de que ele sanar-se-á com a criação de novas burocracias e de novos ministérios. Dispendiosas reuniōes próprias de políticas externas da exibição retórica coadjuvadas por interesses diplomáticos paroquiais tampouco ajudaram. Tudo isso estabiliza o cenário de descrença no Estado. Abandona a sociedade em patamar exposto às ruindades da informação de baixa qualidade.

Se acordos de cooperação mútua para a proteção das nascentes e para o combate ao desmatamento ficam só no papel, vai de vento em popa a economia informal que leva à biopirataria, à lavagem de dinheiro, ao tráfico ilícito de drogas, 
de mercúrio, de armas e ao contrabando de madeiras na Guiana. Se a cooperação vicinal contra o crime organizado inexiste, favor culpar o péssimo uso que o serviço público dos países amazônicos faz das verbas disponíveis e não necessariamente a permanente crise étnica pipocando em Georgetown e Paramaribo.

\section{Conclusão}

A tradição do compadrio diplomático de raízes ibéricas historicamente marginalizou a Guiana e o Suriname. Também o apego aos bailes da corte e às benesses outorgadas pela proximidade com o poder deixam espaços lindeiros amazônicos no abandono. A capital, Brasília, apresenta maior número de delegados da Polícia Federal, de funcionários do Ibama e de generais que aquele presente em toda a Amazônia, que, reitere-se, ocupa 60\% do território nacional.

Acordos bilaterais isolados do contexto regional freqüentemente postergam o processo das estratégias macroeconômicas amazônicas. Abrem-se para políticas imediatistas, raramente compromissadas com a necessária cultura por uma duradoura cooperação vicinal.

Mais do que as controvérsias comerciais, o desinteresse por um mercado comum entre os amazônicos os leva a abandonar esforços por uma cultura de trabalho grupal cuja ausência arruína suas economias. Tão grave quanto o contrabando - seja de armas, do couro, de produtos eletrônicos, de químicos controlados, de madeiras nobres, de pedras preciosas ou dos biodiversos através de portas que se abrem pelo lado de fora da casa amazônica - é a vinculação do crime organizado existente na Hiléia com as máfias trabalhando no Panamá, Haiti, México, Taipé, Miami, Hong-Kong e Nova Déli.

Recebido em 20 de março de 2007 Aprovado em 30 de agosto de 2007

\section{Resumo}

A economia informal no Brasil ligando esse país à Guiana, ao Suriname, à Venezuela e à Guiana Francesa permite pensar numa Amazônia brasileiro-caribenha. O Suriname e a Guiana, essa última sede do CARICOM, convivem com fluxos migratórios de garimpeiros brasileiros fugitivos do desemprego. A economia clandestina dá o seu tom à geopolítica cultural e é mais eficiente, que a diplomacia, em estimular a aproximação entre os países caribenhos.

\section{Abstract}

The Informal economy in Brazil creates strong linkages between the country and Guyana, Surinam, Venezuela and the French Guyana. For this reason it allows us to think of a Caribbean-Brazilian Amazon. Both Surinam and Guyana, the latter a host to CARICOM, 
deal with migration flows of Brazilian miners escaping unemployment. The clandestine economy sets the stage for cultural geopolitics and is more efficient than diplomacy in bringing Caribbean countries closer together.

Palavras-chave: Integração Regional, Economia Informal, Migração Key words: Regional Integration, Informal Economy, Migration 